\title{
DESLOCAMENTOS E IDENTIDADES NO GÓTICO AUSTRALIANO: O CASO DE PICNIC AT HANGING ROCK E PIQUENIQUE NA MONTANHA MISTERIOSA
}

\author{
Luciana Wrege Rassier \\ Universidade Federal de Santa Catarina \\ Florianópolis, Santa Catarina, BR \\ Cynthia Beatrice Costa \\ Universidade Federal de Santa Catarina \\ Florianópolis, Santa Catarina, BR
}

\begin{abstract}
Resumo
O romance Picnic at Hanging Rock, de Joan Lindsay (1967), e sua adaptação cinematográfica homônima dirigida por Peter Weir (1975), comercializada no Brasil como Piquenique na Montanha Misteriosa, têm intrigado leitores e espectadores há mais de quatro décadas. Ambientadas na Austrália rural de 1900, as narrativas ilustram o gênero gótico australiano ao tratar do misterioso desaparecimento de três alunas e uma professora de um internato repressor, durante um piquenique na montanha. Partindo das reflexões de Linda Hutcheon (2011) sobre adaptações, analisamos em que medida as narrativas literária e cinematográfica dialogam; já as reflexões de Susan Bassnett (2006) e Kristi Siegel (2004) sobre relatos de viagem femininos nos permitem pensar as temáticas da sexualidade feminina e do deslocamento no espaço como metáfora da transformação do indivíduo.

Palavras-chave: Picnic at Hanging Rock; Literatura e Cinema; Gótico Australiano; Relatos de Viagem Femininos

\section{DISPLACEMENTS AND IDENTITIES IN THE AUSTRALIAN GOTHIC: THE CASE OF PICNIC AT HANGING ROCK}

\begin{abstract}
The mysteries of the novel Picnic at Hanging Rock, by Joan Lindsay (1967), and its film adaptation of same name, directed by Peter Weir (1975), have been intriguing readers and audiences for more than four decades. Set in the Australian countryside in 1900, both narratives illustrate the Australian Gothic genre by revolving around the mystery of the disappearance of three schoolgirls and a teacher from a repressive boarding school during a picnic at the mountain. Basing our approach on the reflections by Linda Hutcheon (2011) on adaptations we analyze to which extent literary and cinematographic works relate to each other, while the works presented by Susan Bassnett (2006) and Kristi Siegl (2004) on women's travel writing will allow us to approach themes such as female sexuality and travel as a metaphor of transformation.
\end{abstract}

Keywords: Picnic at Hanging Rock; Literature and Cinema; Australian Gothic; Women's Travel Writing

\footnotetext{
"Professora doutora do Departamento de Língua e Literatura Estrangeiras da Universidade Federal de Santa Catarina, atuando principalmente nos seguintes temas: identidades e alteridades, americanidade, tradução, estudos culturais, literatura e cinema. Seu endereço de email é luciana.rassier2010@gmail.com

** Mestre em Literatura e Crítica Literária pela Pontifícia Universidade Católica de São Paulo (2008) e doutora pelo Programa de Pós-Graduação em Estudos da Tradução da Universidade Federal de Santa Catarina. Seu endereço de email é cynthia_costa@uol.com.br
} 
Ao narrar a tensão entre a natureza selvagem e o ser humano, Picnic at Hanging Rock (1967), de Joan Lindsay, insere-se na tradição literária australiana na qual, segundo Gary Clark, "[o] envolvimento com o meio ambiente é uma presença disseminada”" (2007, p. 429). Além disso, o romance dialoga com o gênero gótico, também marcante nessa tradição, e no qual "a sinergia do ambiente sombrio e mentes instáveis subvertem a condescendência civilizada"' (HARRIS, 2008, p. 19). No entanto, o gótico não é adotado por Lindsay ao modo setecentista ou oitocentista, isto é, da forma como se entende o gênero de ficção em voga na Europa - e, sobretudo, na Grã-Bretanha - entre as décadas de $1760 \mathrm{e}$ 1820 , caracterizado por histórias "de mistério e terror" (CUDDON, 1991, p. 381) e pelo emprego do sobrenatural - cujas influências são claras nas obras da inglesa Mary Shelley e dos norte-americanos Nathaniel Hawthorne e Edgar Allan Poe, entre tantos outros autores. Com efeito, Picnic não retrata castelos mal-assombrados nem condes misteriosos, mas integra a chamada "literatura de pesadelo" (MacANDREW, 1979, p. 3), associada a um ambiente desconhecido e repleto de ameaças. Filia-se, assim, ao movimento literário do gótico australiano: marcado pela ausência de uma aristocracia e seus castelos (BYRNES,1988, p. 74), o país colonizado digere a herança gótica europeia à sua maneira, assimilando as formas literárias tradicionais e, ao mesmo tempo, insurgindo-se contra elas, conforme argumenta Gerry Turcotte em Peripheral Fear: Transformations of the Gothic in Australian and Canadian Fiction (2009).

Para Turcotte, por um lado, a compreensão do gótico australiano baseia-se precisamente na noção da Austrália como colônia britânica, herdeira de uma tradição que não corresponde necessariamente a sua realidade de país vasto e selvagem. Por outro lado, a Austrália presta-se particularmente bem à renovação do gótico, devido ao fato de ter sido imaginada, ainda bem antes da chegada dos colonizadores europeus, como "um espaço grotesco, uma terra habitada por monstros" (TURCOTTE, 1998, p.10). Assim sendo, sem assimilar de todo a tradição, mas apropriandose de um de seus principais traços constitutivos - a presença do medo na narrativa -, autores australianos têm explorado a "atração arquetípica entre o civilizado e o bárbaro"3 (TURCOTTE, 2009, p. 22) presente no gótico europeu, adaptando-a ao embate entre o colonizador e o que não é passível de ser colonizado: "O gótico (...) tem tratado, desde a sua origem, de medos e temas que são endêmicos na experiência colonial: isolamento, captura, medo da perseguição e medo do desconhecido"4 (TURCOTTE, 2009, p. 18).

Esse medo do isolamento e do desconhecido é abordado na literatura gótica australiana através de um tema frequente, o desaparecimento de pessoas brancas (portanto, de ascendência europeia) no bush, que se estende por pradarias e florestas no interior do país. Há, nessas narrativas, a sugestão de uma "espacialidade não confiável”"5 (TILLEY, 2012, p. 202), uma dicotomia entre dois mundos incompatíveis - um ordenado e antinatural; outro desordenado e natural - cujas fronteiras se revelam tênues. Esse é precisamente o mote de Picnic at Hanging Rock (1967), da autora australiana Joan Lindsay, que aborda o desaparecimento de jovens virginais e sua professora em uma montanha inóspita. Ao analisar a obra de Lindsay à luz desse tema, Elspeth Tilley lembra que "a ordem cuidadosa deste espaço controlado [o internato retratado no romance] é contraposta a um pano de fundo de uma força desordenadamente natural"6 (2012, p. 207). Em seu Australian Classics: 50 Great Writers and Their Celebrated Work, Jane Gleeson-White elege a obra de Lindsay como um dos marcos da história literária australiana graças à sua combinação única de recursos literários e temas: "Picnic at Hanging Rock trata do medo contagiante, do sugestionável e do comportamento grupal, e joga com as emoções reprimidas de jovens moças isoladas no bush"7 (2010, p. 149).

Iniciado por um aviso aos leitores a respeito da possível veracidade dos fatos que serão relatados, Picnic at Hanging Rock tem como motivo central o Dia de São Valentim (Dia dos Namorados) de 1900, quando um grupo de alunas e duas professoras do internato Mrs. Appleyard's College for Young Ladies, situado na zona rural do estado de Victoria, na extremidade sudeste do país, partem para um piquenique em Hanging Rock, uma antiquíssima formação geológica de origem vulcânica que faz parte das Macedon Ranges, a cerca de 50 quilômetros de Melbourne. Lá, três jovens e uma professora desaparecem sem deixar vestígios. A partir 
daí, a narrativa trata da investigação policial, do impacto desse desaparecimento nas emoções e no comportamento das personagens e da subsequente falência do colégio. Ao longo de seus 17 capítulos, Picnic at Hanging Rock não apresenta soluções para o mistério. Tampouco o Capítulo 18, excluído pelo editor e publicado, avulso, 20 anos mais tarde (TAYLOR, 1987, p. 8), oferece respostas definitivas a respeito do desaparecimento das adolescentes e da professora. Driblando a fórmula de um romance policial tradicional, Lindsay cria um misterioso encadeamento de fatos, cujos segredos nem mesmo o narrador onisciente desvenda.

Apesar do prestígio de que desfruta como clássico moderno da literatura australiana, de ter vendido 350 mil cópias em inglês ao longo dos 15 anos que se seguiram à sua publicação e de ter sido traduzido para o italiano, o espanhol e o francês (GLEESON-WHITE, 2010, p. 151), o romance de Lindsay não alcança a repercussão do filme nele baseado. Fora da Austrália, a tendência é que se chegue ao livro através do longa-metragem homônimo de Peter Weir (1975). Exemplo disso é o fato de que o romance ficou esgotado nos Estados Unidos por um longo período até que, em 2014, uma edição comemorativa do filme em Blu-Ray, que inclui um e-book do romance, foi lançada (CONE, 2014). No Brasil, a situação é semelhante: embora não haja tradução do livro, o filme pode ser encontrado facilmente em DVDs das gravadoras Continental e Spectra Nova.

O longa-metragem, visto por dezenas de milhares de pessoas em todo o mundo (TAYLOR, 1987, p. 2), tem a seu favor tanto o renome do diretor, que viria a dirigir filmes hollywoodianos de alcance mundial, como $A$ Testemunha (Witness, 1985), Sociedade dos Poetas Mortos (Dead Poets Society, 1989) e O Show de Truman (The Truman Show, 1998), quanto um estigma de filme de terror "de arte" (RYAN, 2010, p. 9), consolidado com o passar dos anos.

Em 2015, em homenagem aos 40 anos do lançamento do filme, o National Film \& Sound Archive (NFSA) da Austrália criou uma exposição on-line, em cujo texto de apresentação lemos:

Baseado no romance clássico de Joan Lindsay, Picnic at Hanging Rock combina uma fotogra- fia e direção deslumbrantes com uma trilha sonora etérea. Quando pedidas para citar cinco filmes australianos, muitas pessoas incluem em sua lista Picnic at Hanging Rock. Um sucesso de crítica e público, ele ajudou a estabelecer a reputação internacional de Peter Weir e o lugar da Austrália no cinema mundial. Talvez um fator-chave seja a atração duradoura despertada por seu enredo - o misterioso desaparecimento de algumas alunas e de sua professora nunca é solucionado. ${ }^{8}$ (NFSA, 2015)

Outras razões que fazem com que o longa-metragem continue a suscitar o interesse de públicos variados foram amplamente evocadas na mídia em 2015. Se a escritora australiana Sophie Cunningham (2015) ressalta que Picnic at Hanging Rock pode provocar questionamentos ao longo dos anos pelo fato de se tornar uma "história pessoal", propiciando ao leitor/espectador uma forte identificação à experiência das personagens, a jornalista Jil Hogan, em The Canberra Times, afirma: "É o filme clássico australiano que propõe mais perguntas do que as responde" (2015). De fato, o ponto central do fascínio exercido pela obra de Weir parece ser não só o que ela narra, mas como o faz.

Nessa perspectiva, vale ressaltar que, assim como a literatura, o cinema australiano também cultiva uma releitura própria do gótico, com destaque para o gênero road movie de ação e terror em meio à paisagem desafiadora do bush, como na célebre distopia Mad Max (1979) ou, ainda, em Wolf Creek (2005). Piquenique na Montanha Misteriosa influenciou e reforçou essa tradição: "Como parte do fantastique do cinema gótico australiano, [Piquenique] teve uma grande influência no desenvolvimento da ampla tradição de terror Australis"10 (RYAN, 2010, p. 9), a qual costuma ser bem acolhida pela comunidade cinéfila internacional.

Diante do acima exposto, no presente artigo interrogamo-nos sobre em que medida Picnic at Hanging Rock e Piquenique na Montanha Misteriosa, apesar de serem obras autônomas (Hutcheon, 2011), dialogam ao longo do tempo, além de analisarmos as escolhas e efeitos específicos utilizados na adaptação cinematográfica. Interessa-nos igualmente investigar, a partir das considerações de Susan Bassnett (2006) e Kristi Siegel (2004) sobre relatos de viagem femininos, a articulação entre 
deslocamento no espaço e construção identitária calcada em dicotomias como civilização/barbárie e Europa positiva/restante do mundo negativo. Tais paradigmas binários e simplistas são, conforme aponta Patrick Imbert, inadequados para dar conta das relações complexas entre o Velho Continente e os Novos Mundos (IMBERT, 2015, p. 23).

\section{Trânsitos e diálogos entre narrativas}

Considerando que "a adaptação é uma derivação que não é derivativa, uma obra segunda que não é secundária - ela é sua própria coisa palimpséstica" (Hutcheon, 2011, p. 30), e levando em conta que os códigos e procedimentos cinematográficos são ao mesmo tempo meio e mensagem, conferindo à obra sua própria especificidade (LEVER, 1992, p. 96), torna-se necessário identificar através de quais recursos o longa-metragem de Peter Weir transcodifica a narração e a descrição presentes na narrativa de Joan Lindsay.

A análise da focalização aponta que a figura do narrador observador de Picnic at Hanging Rock também é relevante em sua adaptação cinematográfica, já que a câmera de Weir pode ser considerada observadora: na abertura do filme, paralisa-se diante da imponência do Colégio Appleyard, sugerindo o conservadorismo e a inflexibilidade da instituição; a seguir, ao enquadrar grupos de alunas preparando-se para o piquenique, passa à postura de voyeur, invadindo a intimidade das personagens. Fora da escola, a câmera abre-se em ângulos amplos para abranger grandes porções da paisagem e fecha-se novamente em seu voyeurismo ao observar languidamente as jovens alunas, sem, no entanto, revelar os mistérios que as envolvem. Sobre esse recurso, escreve Michael Bliss: "Uma das qualidades predominantes de Picnic é a ênfase na visão privilegiada da câmera, em virtude da qual ela funciona como um intruso curioso, embora, em última análise, moralmente desinteressado, observando incidentes e personagens, sem, no entanto, intrometer-se"11 (BLISS, 2000, p. 48).

Cabe ressaltar que o tratamento dado no longametragem à natureza selvagem, filmada de maneira por vezes sedutora, por vezes sinistra, reforça a ambiguidade que permeia toda a narrativa: "Para mim, o grande tema era a Natureza, e até a sexualidade das meninas fazia parte dela (...)."12, declara o próprio diretor (WEIR, 2014, p. 75). Além das associações de câmera, outro recurso utilizado para "conectar estados interiores e exteriores", para acentuar e direcionar "as respostas do público a personagens e à ação", é a trilha sonora (HUTCHEON, 2011, p. 70-71). Em Piquenique na Montanha Misteriosa, impera o som inebriante da flauta de Pan, cujo ritmo repetitivo e intoxicante envolve e atormenta o espectador, intensificando a ansiedade gerada pelo desaparecimento inexplicável das personagens e reforçando a atmosfera onírica, que se faz bem mais presente no longa-metragem do que no romance - no qual predomina apenas nos três primeiros capítulos, cuja ação antecede o desaparecimento das adolescentes e a subsequente investigação policial.

Essa atmosfera também resulta da saturação das cores e da utilização de um filtro amarelo na câmera (BLISS, 2000, p. 56), que permite criar um véu sobre cenários, personagens e paisagens. Com imagens feéricas das jovens atrizes revezando-se em enquadramentos lânguidos, entrecortados por relativamente poucos acontecimentos e poucas falas (em sua maioria, retiradas diretamente do romance), Piquenique na Montanha Misteriosa destaca-se na produção cinematográfica mundial pela ousadia com que combina morbidez e sexualidade juvenil feminina - uma combinação que seria retomada, por exemplo, por Sofia Coppola em seu filme de estreia, As Virgens Suicidas (1999), claramente influenciado pelo longa-metragem de Weir (MacDONELL, 2007, p. 132). Outro fator que contribui para o renovado interesse pelo filme é o estranhamento resultante de uma hibridação de gêneros:

Com seu ritmo hipnótico, colegiais virginais em roupas brancas e histeria sexual mal sufocada, Picnic at Hanging Rock sugere o cruzamento de um comercial de Timotei [marca de xampu] com uma história de terror gótico. Se isso lhe parece desconcertante, você não está sozinho. Críticos o julgaram, com frequência, incompreensível. Mas, se Picnic at Hanging Rock não fosse incompreensível, não haveria razão para assistilo; trata-se de um mistério cuja razão de ser é a de ser um mistério, um paradoxo que o torna essencial para cinéfilos. ${ }^{13}$ (MacDONELL, 2007, p. 131) 
O paratexto constituído pelo material promocional do filme, como cartazes e capas dos DVDs, privilegia outro importante recurso: as imagens e os close-ups da personagem Miranda, a mais popular e admirada entre as alunas desaparecidas, que é uma espécie de epicentro gravitacional, em torno da qual orbitam as outras personagens. Nos anos 1970, a então novata Anne-Louise Lambert, com ares de ninfa, se encaixou à perfeição ao papel: "Fãs do filme icônico de Peter Weir ainda a cumprimentam entusiasticamente hoje, 40 anos depois do lançamento do filme à consagração internacional"14 (PERCY, 2015).

Tanto em Picnic at Hanging Rock quanto em Piquenique na Montanha Misteriosa, a beleza de Miranda é associada à imagem de um cisne, ave cuja simbologia remete à fecundidade, ao desejo sexual e ao hermafroditismo, por apresentar características masculinas, como o longo pescoço fálico, e femininas, como o corpo arredondado (CHEVALIER e GHEERBRANT, 1986, p. 307). Essa associação, embora presente no romance, é enfatizada no filme por meio de repetidas sobreposições da imagem de Miranda e da ave, mas também, de modo mais sutil, por objetos como o bibelô em formato de cisne frente ao espelho da penteadeira, no quarto da moça.

Aliás, a simbologia profusa do livro de Lindsay quase sempre encontra eco na adaptação de Weir, a qual, derivativa e, ao mesmo tempo, obra autônoma que é (HUTCHEON, 2011, p. 28), modifica e expande algumas possibilidades de interpretação. O exemplo mais relevante disso talvez seja o realce do homoerotismo no filme. Toda a primeira sequência - em que as alunas do internato preparam-se para o piquenique ao mesmo tempo em que recitam, umas para as outras, declarações de amor distribuídas no Dia de São Valentim - possibilita essa leitura: isoladas na Austrália rural, tendo pouco contato com homens, as moças afeiçoamse umas às outras, cultivando uma intimidade sensual. No caso de Sara, que divide o quarto com Miranda, a afeição beira uma veneração e sugere um amor homossexual. Antes da partida para o piquenique, Miranda a aconselha a aprender a amar outra pessoa ("Você tem de aprender a amar outra pessoa, não só eu, Sara"15), argumentando que não ficará no colégio por muito mais tempo ("Eu não ficarei aqui muito mais tempo"16). No romance, esse conselho é relatado, posteriormente, pelo narrador, não havendo interação direta entre as personagens. Além disso, a ênfase recai tanto na diferença de idade entre as adolescentes - Sara tem apenas 13 anos; Miranda, 18 - quanto no fato de que Sara apoia-se emocionalmente em Miranda, por ser órfã. Essa relação maternal no livro ganha contornos sexuais no filme, cujas atrizes pertencem à mesma faixa etária. Em contrapartida, algumas supressões em relação à narrativa literária conferem à adaptação cinematográfica um teor menos romântico: os dois casamentos (o da professora de francês com um noivo desconhecido e o dos criados do colégio, Minnie e Tom), e o amor não correspondido de Irma por Michael, que ama Miranda.

Esse conjunto de decisões torna o longa-metragem sexualmente mais sugestivo, enquanto o romance desenvolve em maiores detalhes algumas histórias amorosas, com uma notável exceção: no quarto capítulo, há a descrição de um sonho de Mrs. Appleyard no qual ela tenta escalar com o seu falecido marido uma cama flutuando no mar do balneário inglês de Bournemouth. Embora se trate de uma das mais notórias referências à sexualidade feminina no texto reveladora do desejo sexual da repressora e reprimida diretora do internato - a cena não foi incluída filme. Por outro lado, as variadas possibilidades de interpretação do enigmático desaparecimento das jovens e sua professora, que fazem do romance um obra aberta, encontram clara reverberação na obra de Weir, cuja cena final retrata Mrs. Appleyard, a emblemática guardiã dos valores patriarcais europeus e repressivos, olhando fixamente para o nada, derrotada e perdida.

\section{Repressão e transgressão}

Além de se inscreverem na tradição das narrativas góticas, de horror, Picnic at Hanging Rock e Piquenique na Montanha Misteriosa também remetem à tradição de relatos sobre mulheres que, uma vez afastadas de seus lares, colocam-se sob ameaças diversas. Embora não constituam um relato de viagem propriamente dito, as narrativas literária e fílmica se aproximam desse gênero tanto por sua trama de incursão pelo inóspito bush australiano (caracterizado pela paisagem árida e 
de vegetação esparsa captada em panorâmicas no filme, que foi gravado in loco) quanto pela transformação interior dos viajantes ocasionada pelo deslocamento, "não porque seja causa e efeito", dizem Lean, Staif e Waterton em sua introdução a Travel and Transformation, "mas porque todo movimento provoca mudanças"1717 (2014, p. 15). Essa passagem de um ambiente enclausurado rumo a um espaço de liberdade é bastante frequente em relatos de viagem femininos, como lembra Susan Bassnett:

Um dos temas recorrentes em muitos estudos sobre mulheres viajantes é a diferença entre as suas vidas em casa e na estrada. Mulheres viajantes são apresentadas, com frequência, como tendo conseguido, de alguma forma, libertarse das amarras da sociedade contemporânea, tomando consciência de seu potencial fora dos limites de uma ordem social restritiva. Tal leitura propõe que as mulheres que se afligiam com as restrições da domesticidade podiam encontrar um escape por meio de viagens. ${ }^{18}$ (2006, pp. 233-234).

Ao refletir sobre a "retórica de perigo" ("rhetoric of peril") dirigida a mulheres viajantes, Kristi Siegel (2004, p. 60-61) enfatiza que os cuidados excessivos para com o deslocamento feminino encontram respaldo na tradição literária ocidental ${ }^{19}$. Com efeito, as alunas do Appleyard College for Young Ladies são devidamente avisadas pela diretora do internato - tanto no romance quanto no filme - sobre todos os terríveis riscos e ameaças de seu destino, tais como cobras e outros animais peçonhentos. No entanto, as estudantes partem eufóricas, sendo nítido o desejo de ir além dos muros do colégio e viver algo inusitado. Assim, a um status quo inicial sucede uma possibilidade de transformação, graças ao deslocamento para um espaço desconhecido (LEAN, STAIFF e WATERTON, 2014, p. 229).

Essa noção de escape feminino é claramente perceptível no livro de Lindsay e em sua adaptação cinematográfica. Somos apresentados, no início de ambas as narrativas, à "prisão" em que vivem as moças: o Appleyard College, uma instituição reconhecida à qual pais abastados e interessados em uma educação "europeia" enviam as filhas. Esse espaço é dominado pela figura autoritária e imponente de Mrs. Appleyard ${ }^{20}$, a diretora inglesa, motivada por sua ambição financeira e por seu desejo de status social. Sua postura conservadora é sublinhada no romance por meio da descrição da mansão escolhida para abrigar o internato: "O Appleyard College já era, no ano de 1900, um anacronismo arquitetônico no bush australiano - irremediavelmente deslocado no tempo e espaço" ${ }^{21}$ (LINDSAY, 2013, p. 8). Mrs. Appleyard e seu internato representam o velho mundo, uma Europa oitocentista em meio à natureza selvagem de um país jovem e pouco explorado. Simbolizam também o cerceamento característico das instituições que, em nome do coletivo, restringem as liberdades individuais.

Os trajes usados pelas alunas correspondem ao ambiente opressor da escola e, de maneira mais geral, da sociedade da época. No calor da Austrália - ao qual o livro faz constantes referências, e que o filme retrata através de uma luminosidade claríssima, saturada - é compreensível que as adolescentes se sintam desconfortáveis com a moda importada da Europa. Por baixo dos vestidos de verão, elas usam espartilhos que lhes oprimem a respiração, meias de algodão, botas de couro e anáguas volumosas. No romance, fazendo concessão ao calor do dia, Mrs. Appleyard permite que as moças retirem as luvas após passarem pela cidadezinha de Woodend no caminho para Hanging Rock, o que mostra que elas devem preservar a compostura até o seu último contato com a civilização. No filme, essa pequena libertação é sensivelmente adaptada: em meio à poeira avermelhada levantada pelo coche na passagem por Woodend, as jovens retiram as luvas com bastante entusiasmo, suscitando assobios e gracejos por parte dos rapazes.

De um ponto de vista simbólico, é importante salientar, por um lado, que todas as alunas e a professora de francês vão ao piquenique de branco, "a cor da pureza" (LEXICON, 1998, p. 38), enquanto que Miss McCraw, que desaparecerá na montanha, veste-se de ocre, cor que remete ao tom avermelhado do solo da região. O piquenique acontece em um dia de forte valor simbólico do ponto de vista da tradição europeia: 14 de fevereiro, dia de São Valentim. Tal celebração, calcada no calendário cristão, é uma reatualização da festa pagã 
consagrada à celebração da fertilidade feminina através de Hera - na mitologia grega, esposa de Zeus e deusa do casamento e da maternidade, conhecida em Roma como Juno Februa, denominação que originou o nome do mês, fevereiro (MONAGHAN, 2004, p. 63). Na era pré-cristã, nesse período do ano também acontecia a festividade romana conhecida como Lupercália, um antigo ritual de purificação e de passagem colocado sob a égide de Lupércio, correspondente, na mitologia grega, a Pan, deus que caçava e dançava rodeado de ninfas. Essa inserção em um tempo mítico também é sugerida pelo fato de os relógios deixarem de funcionar ao meio-dia (devido ao magnetismo da rocha, especula Miss McCraw antes de desaparecer). Nesse sentido, vale ressaltar que, já antes da ida à montanha, a jovem Miranda renunciara a usar o seu relógio por não suportar o tique-taque sobre o seu coração ("Não suporto ouvi -lo tiquetaqueando o dia todo sobre o meu coração"22; LINDSAY, 2013, p. 21), conforme explica à professora de francês. Essa é uma pista de que a sua busca pela libertação começara bem antes, o que explicaria a determinação e segurança inabalável com que a jovem sobe a montanha. Miranda já estaria sendo guiada pelas batidas de seu coração, por seu ritmo biológico, por suas pulsões naturais e seus desejos, e não mais pelo tempo coletivo da civilização.

Uma vez em Hanging Rock, quatro jovens pedem permissão para se afastar do grupo e do local do piquenique a fim de explorar o rochedo vulcânico: a angelical Miranda, a inteligente Marion, a linda Irma e Edith. Se esta é feiosa, roliça e inconveniente, Miranda é seu oposto. Quando se despede da professora de francês com um aceno, esta a associa às pinturas de Botticelli. No filme, a câmera mostra a reprodução da imagem que Mademoiselle tem em mente: trata-se, precisamente, de "O Nascimento de Vênus" (1486), que representa a irrupção das forças arquetípicas do Feminino. Ao subirem pela montanha pedregosa, as quatro moças entram em contato direto com as entranhas da Mãe Terra, cujas cavernas obscuras e fendas remetem de maneira bastante evidente aos órgãos sexuais femininos. Na adaptação de Weir, o deslocamento do grupo nesses espaços exíguos é filmado de cima, dando a sensação de que as jovens são espiadas por alguém. Levadas pelo calor e pelo esforço físico exigido pela escalada, Miranda, Marion e Irma tiram os sapatos e as meias e os amarram à cintura, o que choca Edith, que permanece como está. A seguir, entrando em contato ainda mais profundo com a natureza, deitam-se no chão, em um platô circular, ao pé do rochedo fálico que se ergue, ameaçador, sobre elas, numa clara alusão às virgens sacrificiais da mitologia clássica (DALY, 2009, p. 11). Ali adormecem sob o sol escaldante e, ao despertarem, em um estado de torpor, Miranda, Marion e Irma seguem, descalças, escalando as rochas em silêncio e sem olhar para trás, insensíveis aos chamados de Edith, como se atendessem a um apelo mais forte. No filme, o movimento das moças é filmado em câmera lenta, acentuando a atmosfera onírica da cena. O caráter simbólico de tal deslocamento é intensificado pelo som da flauta de Pan, na medida em que esse deus grego, que habitava cavernas nas montanhas, se mantinha à espreita de quem se aventurasse nesses arredores, a fim de suscitar-lhe descontrole através do pânico.

A única das quatro moças a sucumbir ao pânico é Edith, a qual, assustada com o comportamento aparentemente sem sentido das três colegas, ao retornar em desabalada corrida ao local do piquenique, avista Miss McCraw subindo as rochas sem a saia, apenas de anáguas. No Capítulo 18, que ficou de fora da publicação original do livro e não consta no filme, as desaparecidas Miranda, Irma, Marion e a professora McCraw retiram os espartilhos no alto da rocha, seguindo a sugestão de Marion: "Por que não nos livramos desses acessórios absurdos? Afinal, temos costelas suficientes para nos manter eretas"23 (LINDSAY, 1987, p. 27). Os espartilhos, atirados por Miranda do alto do precipício, flutuam no ar, remetendo a uma sensação de "delicioso frescor e liberdade" ${ }^{24}$, que acompanha a renúncia à repressão do corpo feminino. Irma, a única das quatro desaparecidas a voltar à civilização, é encontrada na montanha sem seu espartilho, fato que é significativamente silenciado no relato do médico que a examina, o qual atesta sua virgindade preservada. Após uma conversa constrangedora com a diretora do internato, durante a qual Irma expressa sua autonomia e desejo de liberdade ("Tenho dezessete anos, Mrs. Appleyard. Grande o suficiente para aprender algo 
sobre o mundo"25 - LINDSAY, 2013, p. 132), a moça dirige-se ao ginásio, onde há uma aula de dança. Em meio às outras jovens uniformizadas, destaca-se por sua beleza e vestimenta requintada, com chapéu e capa escarlates ("cor da vida, do amor, do calor, da paixão fervorosa e da fecundidade" - LEXICON, 1990, 203), evidências da transformação por que passou no período do seu desaparecimento. A rígida coreografia ensinada às alunas opõe-se à dança solta e liberta de Irma e das desaparecidas em Hanging Rock, evidenciando que o ginásio, chamado pelas alunas de "Câmara dos Horrores", não é um local dedicado ao descobrimento e desenvolvimento corporal das adolescentes, mas um reduto de tortura e repressão.

Renascida após um drama sobre-humano (oito dias na montanha, sem água nem comida), Irma não é bem-vinda pelas colegas; sua visita desencadeia um episódio de mal-estar e histeria coletiva, no qual as jovens alunas a bombardeiam com perguntas a respeito do desaparecimento de Miranda, Marion e Miss McCraw. Ao contrapor-se ao sistema repressor do colégio, Irma é colocada no papel de inimigo a ser combatido pela coletividade. Sua presença denuncia a falta de espontaneidade e de liberdade sexual. De vítima sobrevivente de uma tragédia, ela passa a vilã, sendo agredida fisicamente pelas colegas. Esse ataque coletivo parece corresponder à necessidade de restaurar a aparente afinidade cultivada entre as alunas, que se voltam, em conluio, contra um inimigo comum - em uma alusão evidente ao mecanismo universal do bode expiatório, analisado por René Girard, segundo o qual "o herói mítico é uma vítima unânime (...). O linchamento (...) reconcilia a comunidade, e a personagem que foi linchada passa por ser muito má pois causou a violência" (GIRARD, 2008, p. 7).

Declarada "intacta" pelo médico, sabemos que a transformação de Irma não foi física, mas emocional: ela se libertou da repressão do colégio. As outras alunas, ainda prisioneiras, não se regozijam de sua liberdade e a acusam de esconder segredos. O que Irma saberia que elas ainda não sabem? No romance, a aluna Blanche - cujo nome "Branca" alude à pureza e, portanto, ao antagonismo com os tons avermelhadas das roupas de Irma - resume a desconfiança para com a ex-colega:
"Irma gosta de ter segredos de adulto. Ela sempre gostou"26 (LINDSAY, 203, p. 138). Os "segredos de adulto", pode-se imaginar, são os segredos do sexo e da liberdade sobre o próprio corpo - o extremo oposto do que é a norma no internato.

\section{Considerações finais}

O romance Picnic at Hanging Rock (1967), de Joan Lindsay, e sua adaptação cinematográfica homônima (1975), de Peter Weir, integram a tradição literária e cinematográfica australiana ao adequarem temática e recursos góticos ao imaginário local, retratando o desaparecimento de jovens colegiais e sua professora na aterradora e inóspita Hanging Rock, em pleno bush, cujo caráter selvagem contrasta com a atmosfera repressora e rígida do Mrs. Appleyard's College for Young Ladies. Ambas narrativas também dialogam com a tradição de relatos de viagem femininos na medida em que põem em cena o deslocamento de um espaço enclausurado rumo a um espaço desconhecido que propicia uma transformação radical do indivíduo e de sua visão de mundo. Longe das amarras do internato, livres das vestimentas opressoras, as adolescentes e sua professora deixam para trás os ditames civilizatórios para seguir rumo à conquista do próprio corpo e da sexualidade.

Retratando de maneira singular o rito de passagem da adolescência, a simbologia iniciática que envolve o desaparecimento das adolescentes remete a uma morte simbólica, em um tempo e um espaço mitológicos, relacionados a antigos rituais de fertilidade. A narrativa fílmica reforça a atmosfera onírica presente no romance, principalmente através da trilha sonora inebriante marcada pela flauta de Pan e da caracterização das adolescentes como ninfas, ou seja, divindades femininas ligadas à Natureza, à beleza e aos prazeres do corpo caracterização que reatualiza elementos arquetípicos da psique humana. Outra especificidade do diálogo entre o longa-metragem e a narrativa literária é o realce dado por Peter Weir aos laços homoeróticos entre a protagonista Miranda e a órfã Sara, revelando assim transgressões ao rígido código moral que aconteciam dentro do Appleyard's College for Young Ladies, antes do misterioso desparecimento. 


\section{Picnic at Hanging Rock e Piquenique na Montanha} Misteriosa são narrativas que transitam entre gêneros e tradições literárias e cinematográficas, operando deslocamentos e reatualizações no modo de contar o sempiterno embate entre as pulsões libertárias de jovens adolescentes e a ordem civilizatória coercitiva.

\section{Notas}

1. Tradução nossa de: "Engagement with environment is a pervasive presence in Australian literature". Todas as traduções de citações do presente artigo, a menos que indicado, foram realizadas por nós.

2. "The synergy of the bleak setting and unstable minds subverts any civilized complacency."

3. "archetypal pull between the civilized and the barbaric"

4. "The Gothic, in other words, has from its inception dealt with fears and themes that are endemic in the colonial experience: isolation, entrapment, fear of pursuit and fear of the unkown."

5. "unreliable spatiality"

6. "(...) the careful order of this controlled space is set against an encroaching background of disorderly natural force"

7. "Picnic at Hanging Rock is concerned with the contagion of fear, with suggestibility and the behavior of groups, and plays on the suppressed emotions and sexual yearnings of young girls isolated in the bush."

8. "Based on the classic novel by Joan Lindsay, Picnic at Hanging Rock combines stunning cinematography and direction with an ethereal score. When asked to name five Australian films, from any time, many people would include Picnic at Hanging Rock in their list. A critical and popular success, it helped establish Peter Weir's international reputation and Australia's place in world cinema. Perhaps a key factor in its enduring appeal is its plot - the mysterious disappearance of several schoolgirls and their teacher is never solved."

9. "It's the classic Australian flick that poses more questions than it answers."

10. "Picnic as part of Australian fantastique of Gothic cinema which has had a major influence on the development of a broad tradition of terror Australis."

11. "One of the Picnic's overriding qualities is the emphasis on the camera's privileged view, by virtue of which it functions as a curious, but, ultimately, morally disinterested outsider, regarding incidents and characters but not intruding upon them."

12. "For me the grand theme was Nature, and even the girls' sexuality was as much a part of that (...)."
13. "With its hypnotic pace, virginal white clad schoolgirls, and barely smothered sexual hysteria, Picnic at Hanging Rock suggests a Timotei commercial crossed with a gothic horror story. If that sounds baffling, you're not alone. Critics have often found it incomprehensible. But if Picnic at Hanging Rock wasn't incomprehensible, there would be no reason to watch it; it's a mystery whose entire point is that it's a mystery, a paradox that makes it essential viewing for film buffs."

14. "Fans of Peter Weir's iconic movie still greet her enthusiastically even now, 40 years since the movie was released to international acclaim."

15. "You must learn to love someone else, apart from me, Sara."

16. "I won’t be here much longer."

17. "Not cause and effect, but interchangeable because all movement changes."

18. "One of the themes running through many popular studies of women travellers is the difference between their lives at home and life on the road. Women travellers are often presented as having been somehow able to break free of the constraints of contemporary society, realizing their potential once outside the boundaries of a restrictive social order. Such a reading proposes that women who chafed at the constraints of domesticity could find escape through travel."

19. Exemplo célebre é o conto Chapeuzinho Vermelho e o Lobo Mau - uma metáfora da sedução e da criança púbere em busca do prazer e da descoberta sexual, de acordo com a reflexão de Bruno Bettelheim (2002, p. 128) Chapeuzinho Vermelho, assim como as estudantes retratadas no livro e no filme, "não teme o mundo lá fora, antes reconhece a sua beleza" (BETTELHEIM, 2002, p. 110).

20. "Sra. Pátio de Maçãs", cujo sobrenome por si só é bastante sugestivo, dada a carga simbólica da maçã como a fruta dos desejos terrestres e/ou da fonte do conhecimento, entre outras possíveis interpretações (CIRLOT, 1992, p. 297); as maçãs/os desejos no colégio estariam, assim, "domesticadas", encerradas em um pátio.

21. "Appleyard College was already in the year nineteen hundred an architectural anachronism in the Australian bush - a hopeless misfit in time and place."

22. "I can't stand hearing it ticking all day long just above my heart".

23. "Why don't we all get out of these absurd garments? After all, we have plenty of ribs to keep us vertical".

24. "delicious coolness and freedom" 
25. "I am seventeen, Mrs. Appleyard. Old enough to learn something from the world."

26. "Irma likes to have grown-up secrets. She always did."

\section{Referências}

BASSNETT, Susan. Travel Writing and Gender. In: HULME, Peters; YOUNGS, Tim (ed.). Travel Writing. Cambridge: Cambridge University Press, 2006, p. 225241.

BETTElHeim, Bruno. A Psicanálise dos Contos de Fada. Trad. de Arlene Caetano. São Paulo: Paz \& Terra, 2002.

BLISS, Michel. Dreams Within a Dream - the Films of Peter Weir. Carbondale: Southern Illinois University, 2000.

BYRNES, Paul. "Australia's Gothic World Revealed". Entrevista concedida a Frank Moorhouse e Mike Thornhill. Sydney Morning Herald, 27 de fevereiro de 1988, p. 74-75.

CHEVALIER, Jean (dir.); GHEERBRANT (colab.). Diccionário de los Símbolos. Barcelona: Herder, 1986.

CIRLOT, Juan-Eduardo. Diccionário de Símbolos. Barcelona: Editorial Labor, 1992.

CLARK, Gary. Environmental Themes in Australian Literature. In: BIRNS, Nicholas; MCNEER, Rebecca (ed.). A Companion to Australian Literature Since 1900. Rochester/NY: Camden House, 2007. p. 429-444.

CONE, Nathan. Nearly 40 Years Later, Secrets of "Hanging Rock" Still Beguiling. In: Texas Public Radio. Disponível em: < http://tpr.org/post/nearly-40-yearslater-secrets-hanging-rock-still-beguiling\#stream $>$. Último acesso em 25 set. 2016.

CUDDON, John. The Peguin Dictionary of Literary Terms and Literary Theory. London: Penguin Books, 1991.

CUNNINGHAM, Sophie; LEY, James. AUSTRALIAN LITERATURE 102: JOAN LINDSAY: PICNIC AT HANGING ROCK [Vídeo]. Disponível em: <https:// www.youtube.com/watch? $\mathrm{v}=$ Yssdjo9kHdc $>$. Último acesso em 25 set. 2016.

DALY, Kathleen N. Greek and Roman Mythology A to Z. Nova York: Chelsea House, 2009.

GIRARD, René. O Bode Expiatório e Deus [E-book]. Trad. de Márcio Meruje. Covilhã/Portugal: LusoSofia, 2008.

GLEESON-WHITE, Jane. Australian Classics: 50 Great Writers and Their Celebrated Work. Sydney: Allen \& Unwin, 2010.

GRAEME, D.; HIST, J.B.; MACINTYRE, S. (org.). The Oxford Companion to Australian History. Oxford: Oxford University Press, 1998.
HARRIS, Jason Marc. Folklore and the Fantastic in the Nineteenth-Century British Fiction. Burlington/VT: Ashgate, 2008.

HOGAN, Jil. Stars come to Canberra for the fortieth anniversary of Picnic at Hanging Rock. In: The Canberra Times On-Line. Disponível em: <http:// www.canberratimes.com.au/act-news/canberra-life/ stars-come-to-canberra-for-the-fortieth-anniversaryof-picnic-at-hanging-rock-20150731-gip3e9.html> . Último acesso em 25 set. 2016.

HUTCHEON, Linda. Uma teoria da adaptação. Trad. de André Cechinel. Florianópolis/SC: Editora UFSC, 2011.

IMBERT, Patrick. Comparando o Canadá e o Brasil: da exclusão ao transcultural. In: BERND, Zilá. IMBERT, Patrick (orgs.). Encontros transculturais Brasil-Canadá. Porto Alegre: Tomo Editorial, p.21-40.

LEAN, Garth; STAIFF, Russel; WATERTON, Emma (ed.). Travel and Transformation. Farnham/Inglaterra: Ashgate, 2014.

LEVER, Yves. Lanalyse filmique. Montreal: Editions Boréal, 1992.

LEXICON, Herder. Dicionário de Símbolos. São Paulo: Cultrix, 1998.

LINDSAY, Joan. Chapter 18. In: ; TAYLOR, John; ROUSSEAU, Yvonne. The Secret of Hanging Rock. Londres: Angus \& Robertson Publishers, 1987.

Picnic at Hanging Rock [E-book]. Melbourne: Penguin Random House, 2013.

MacANDREW, Elizabeth. The Gothic Tradition in Literature. Nova York: Columbia University Press, 1979.

MacDONELL, Nancy. In the Know - The Classic Guide to Being Cultured and Cool [E-book]. Londres: Penguin Books, 2007.

MONAGHAN, Patricia. The Goddess Path - Myths, Invocations and Rituals. St. Paul/MN: Llewellyn Publications, 2014.

PERCY, Karen. Picnic at Hanging Rock: Fans still love "Miranda" four decades after release of movie. In: ABC News. Disponível em: <http://www.abc.net. au/news/2015-08-07/fans-still-love-miranda-frompicnic-at-hanging-rock-40-years-on/6672356>. Último acesso em 25 set. 2016.

PICNIC AT HANGING ROCK: 40 YEARS OF MYSTERY. In: NFSA. Dinsponível em: <http://www.nfsa.gov.au/ visit-us/exhibitions-presentations/picnic-at-hangingrock-exhibition/> Último acesso em 25 set. 2016.

RYAN, Mark D. Towards an understanding of Australian genre cinema and entertainment: beyond the 
limitations of "Ozploitation" discourse. In: Continuum: Journal of Media \& Cultural Studies, v. 24, n. 6, 2010. p 843-854.

SAVIOUR, Catania. The Hanging Rock Piper: Weir, Lindsay, and the Spectral Fluidity of Nothing. Literature/Film Quarterly, abril, 2012.

SIEGEL, Kristi (ed.). Gender, Genre \& Identity in Women's Travel Writing. Nova York: Peter Lang, 2004.

TAYLOR, John. Introduction. In: The Secret of Hanging Rock. ; LINDSAY, Joan; ROUSSEAU, Yvonne. The Secret of Hanging Rock. Londres: Angus \& Robertson Publishers, 1987. p. 7-18.

TILLEY, Elspeth. Cross/Cultures 152 - White Vanishing: Rethinking Australia's Lost-in-the-Bush Myth. Amsterdã/Nova York: Rodopi, 2012.

TURCOTTE, G. Australian Gothic. In: MUlveY, M. R. (ed.). The Handbook to Gothic Literature. Londres: Macmillan Basingstoke, 1998. p.10-22.

. Peripheral Fear: Transformations of the Gothic in Australian and Canadian Fiction. Oxford: Peter Lang Publishing, 2009.

WEIR, Peter. Piquenique na Montanha Misteriosa (1975) [Filme]. Direção de Peter Weir, roteiro de Cliff Green. Santana do Parnaíba/SP, 2009. 105 min. DVD

WEIR, Peter. Towards the Centre, by Tom Ryan and Brian McFarlane (1981). In: TIBETTS, J. C. Peter Weir: Interviews. Jackson: University Press of Mississippi, 2014. p. 133-147. 